\title{
Want Change Not Coins
}

\author{
Maryam Soltani ${ }^{1}$ (D) Kurt Lindeman $^{1}$
}

Received: 25 January 2018 / Accepted: 26 February 2018 / Published online: 9 March 2018

(C) Academic Psychiatry 2018

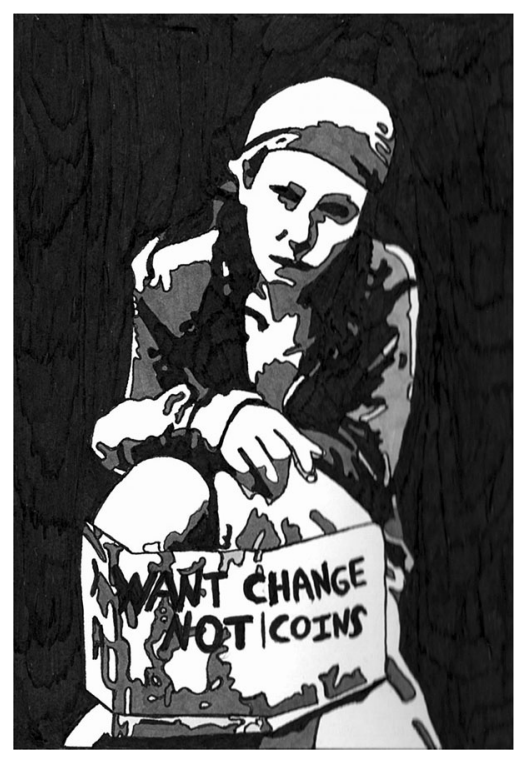

Homelessness deprives individuals of...basic needs, exposing them to risky, unpredictable environments. In short, homelessness is more than the absence of physical shelter, it is a stress-filled, dehumanizing, dangerous circumstance in which individuals are at high risk of being witness to or victims of a wide range of violent events... - Fitzpatrick, LaGory, and Ritchey [1]

I walked into the patient waiting room and called her name, a young woman in her early 20 s. She stood and walked towards me, her eyes meeting mine fleetingly. In the exam room, I asked her, "What brings you in to see me?" She said, "I hear voices." During the course of our interview, I noticed her exaggerated mannerisms: initially soft-spoken with little eye contact, she shifted to yelling and crying, "The voices are driving me crazy!" She covered her ears and sat in a fetal

Maryam Soltani msoltani@ucsd.edu

1 University of California, San Diego, CA, USA position, rocking back and forth in the chair and talking to herself. She grew up in shelters and defying the safety that shelter connotes, recounted a traumatic past. Her dramatic behavior was not psychotic. Her thinking was logical and sequential. Accustomed to being ignored and neglected, I think she learned to be dramatic to get attention. She wanted me to understand that she no longer wanted to be a mother living on the streets with a fiancé and young child.

After interviewing her, I spoke with my attending. When I returned to the exam room with my attending, her behavior became more histrionic; she stopped answering questions and talked to herself. After my attending and I told her about our plan, she became relaxed, spoke to us, and expressed gratitude.

The image represents the homeless population that our medical clinic serves in San Diego County. Our patients have survived unimaginable trauma in "shelters" and on the streets. People "want" to be homeless is a misconception. We learn from the homeless that many want change, but find that, once homeless, it is difficult to find housing and employment. How can a person present to a job interview after sleeping on the concrete and wearing unwashed clothing and unbathed? Who 
would hire her? How do you secure a place to live without income? The homeless would be grateful to have a home, regular access to food, clothing, and gainful employment. But their life circumstances make it extremely difficult, if not near impossible, to achieve this change. Homelessness is a dehumanizing experience that immerses people in physical and emotional circumstances that the rest of society shuns or turns away from in fear and disgust.

We have learned that traumatic experience and/or witnessing trauma itself is a risk factor for mental health problems leading to homelessness. Our patients are wary of other people, mistrustful, and feel defeated. They suffer from a number of mental health conditions including but not limited to post traumatic stress disorder, depression, anxiety, and somatic syndromes. Health care providers have to work to earn their trust. In addition to words, they often communicate through their symptoms and their behavior. Could the behavior or somatic complaints be their way of expressing emotions that they cannot articulate? The most important information is often not what is explicitly stated, but rather what is implicitly expressed through physical and emotional symptoms and expressions. We should remind ourselves that we all want the same things: food, shelter, caring, love, and respect, and that we can all, through war, disaster, and physical and emotional trauma, be deprived in one or all of these ways. In this way, homelessness is a false distinction that separates a group of people from society. Recognizing the false distinction can lead to respect, compassion, and trust, a bridge from the street to a home of care.

Acknowledgments The authors thank Greg Gurnick for his editorial comments.

The drawing is based upon the photograph taken by John Conn published in the British Journal of Photography.

Author Contributions The art was done by Maryam Soltani. The essay was done by Maryam Soltani and Kurt Lindeman.

\section{Reference}

1. Fitzpatrick KM, LaGory ME, Ritchey FJ. Dangerous places: exposure to violence and its mental health consequences for the homeless. Am J Orthop. 1999;69:438-47. 